\title{
Packaged Millimeter Wave Thermal MEMS Switches
}

\author{
P. Blondy*,D. Mercier*, D. Cros*, P. Guillon* \\ P. Rey**, P. Charvet**, B. Diem** \\ C. Zanchi***, L. Lapierre***, J. Sombrin***, J.B. Quoirin**** \\ Tel: 0555457731 - Fax: 0555457649 - email: pblondy@ircom.unilim.fr \\ * IRCOM, Faculté des Sciences, 123 avenue A. Thomas, 87000 LIMOGES FRANCE \\ ** CEA-LETI, 17 rue des Martyrs, 38054 GRENOBLE Cedex 9 \\ *** CNES, 18 Avenue E. Belin, 31000 TOULOUSE \\ **** ST Microelectronics, rue P. et M. Curie, 37071 TOURS
}

\begin{abstract}
This abstract describes MEMS thermally actuated millimeter wave switches. The switches are constructed using a stress controlled dielectric membrane, with patterned metallic contacts. The resulting switches can be operated at low voltage, without sacrificing the spring constant. The structure allows to build resistive switches up to millimeter wave. Full wave simulations were performed using FEM and MoM codes, and agree well with measurements. A wafer scale packaging technique has been developed to protect the components during the dicing stage, and for long term durability. The measured isolation are better than $35 \mathrm{~dB}$ between 30 and $40 \mathrm{GHz}$.
\end{abstract}

\section{INTRODUCTION}

MEMS switches are receiving much interest for millimeter wave applications. They are expected to offer higher performances regarding linearity, power consumption, and loss compared with semi conductors equivalent. Most structures are relying on electrostatically actuated beams combined with CPW circuits[1-4]. These switches have high actuation voltages, usually over $10 \mathrm{~V}$. For lower voltages, the spring constant has to be strongly reduced, and stiction problems can occur. Thermal actuation [5] can be a good alternative to electrostatic switching, with obviously lower speed but also lower voltage. Still, the energy, necessary for switching, can be comparable to electrostatic components. However, a thermal actuation is by definition temperature sensitive, therefore the switches presented in this abstract are using a thermally triggered operation. That is to say that they are insensitive to heating below a defined temperature, and that they snap down above this temperature.

Using this principle of actuation, we investigated the potential of this technology for millimeter wave switching. The targeted applications are redundancy switching between two satellite receiver chains, where loss and linearity are of prime importance. Another feature is that the number of switching cycles is not a real issue for this application.

\section{STRUCTURE}

The switches are constructed using a stress controlled buckling dielectric fixed-fixed beam (fig. 1), on a high resistivity $450 \mu \mathrm{m}$ thick silicon substrate [6].

The bridge height is about $4.5 \mu \mathrm{m}$ at the center of the beam, and a patterned center top electrode is moved down to contact signal lines under the bridge. When the components are released, a micromachined high resistivity silicon cavity is glued on top of the wafer, with access holes from the top to allow dicing, and connection. The cavity is $15 \mu \mathrm{m}$ high, not metallized, and simply provides mechanical protection from the outside, in conventional atmosphere. The transverse section is shown on fig. 2.

The measured switching voltage is between 5 and $6 \mathrm{~V}$. The resistors on each side of the beam are connected in series for testing purpose, and therefore, this actuation voltage is divided by two when the resistors are connected in parallel. Turn off time is $50 \mu \mathrm{s}$, while turn on time is $300 \mu \mathrm{s}$, (measured with DC voltage applied between the electrodes). This difference can be explained by the fact that the 'off state' is detected as soon as the contact is lost, while the on state requires to go trough the complete heating process. 


\section{E-M MODELLING AND MEASUREMENTS}

The operation of the switch has been validated between 30 and $40 \mathrm{GHz}$ in a series coplanar waveguide (CPW) configuration. The layout of the test structure is shown fig. 3. This structure was simulated using an FEM code developed at the laboratory and a commercially available MoM code (Agilent Momentum). The whole structure was simulated taking into account for the bridge dielectric and the contact electrode. The off state is presented on fig. 4, with good agreement between simulation and measurements. Following this step, we designed a millimeter wave double series switch, using the same CPW feeding line. The layout of the structure is presented on fig. 5.

The measured off state response can be seen on fig. 6 . The behavior is dominated by the off state series capacitance, while the on state is dominated by the contact resistance. This resistance can be hardly predicted by simulation, since it depends on materials involved and on contact pressure induced by the actuator. The measured on state loss are $2 \mathrm{~dB}$ at $35 \mathrm{GHz}$. They include $4 \mathrm{~mm}$ feeding line loss. To determine the loss of the switch itself, we compared the loss of the switch in the on state with a through CPW line of the same dimensions. The results are reported on figure 7. Losses associated with the switch in itself are less than $0.2 \mathrm{~dB}$, over the whole band.

\section{CONCLUSION}

Thermally actuated switches have been simulated fabricated and measured. They have low actuation voltage, high isolation, and mechanical protection. By using full wave simulations, this type of switch has been optimized for millimeter wave operation. Losses associated with the switch in itself are at least one order of magnitude lower than the feeding lines. Future work includes association of series and parallel association of these structures in more complicated circuits in a single package.

\section{REFERENCES}

[1] C. Goldsmith, T.H. Lin, B. Powers, W.R. Wu, and B. Norwell, "Micromechanical membrane switches for microwave applications", IEEE MTT-S Digest, 1995, pp 91-94.

[2] J. B. Muldavin, G.M. Rebeiz, "High isolation inductively tuned X band MEMS shunt switches", IEEE MTT-S Digest 2000, pp 169-172.

[3] N.S. Barker, "Distributed MEMS Transmission lines", PhD dissertation, 1999, the University of Michigan.

[4] S. Pacheco, L. P. B. Katehi, C. T. Nguyen, "Design of low actuation voltage RF Mems Switches", IEEE MTT-S Digest 2000, pp 165-168.

[5] Z. Feng et al, "Design and modeling of RF MEMS tunable capacitors using electrothermal actuators", IEEE MTTS Digest 1999, pp 1507-1510

[6] P.L. Charvet, B. Diem, M. Dufour, J.L. Morand, J.B. Quoirin, "Teta Switch: Micro Commutateur a declenchement pour application de puissance", EPF 2000, Lille, France, Nov. 2000.
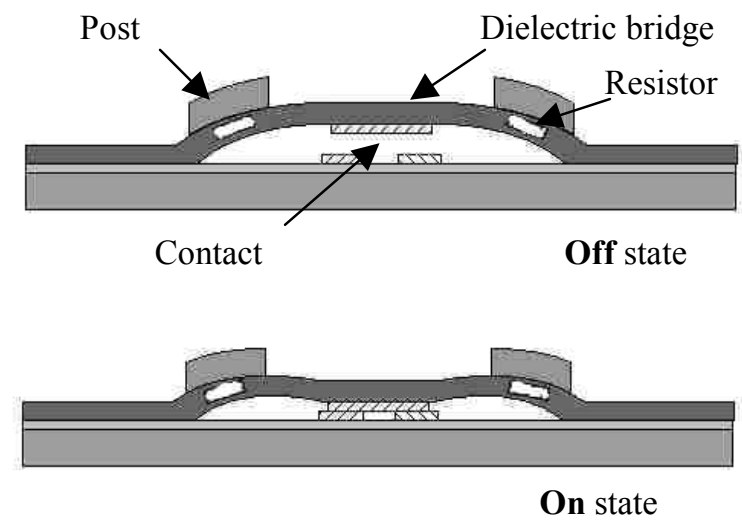

Fig. 1.Principle of operation 


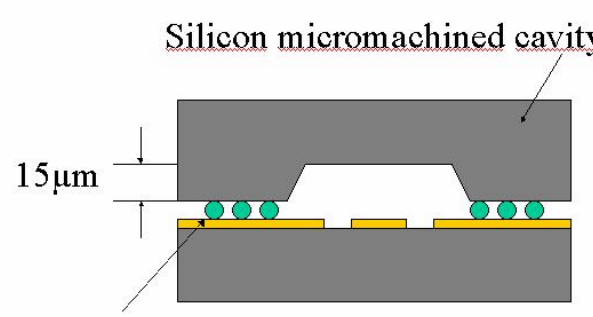

Glue

Fig. 2 Cross section of the packaged switch

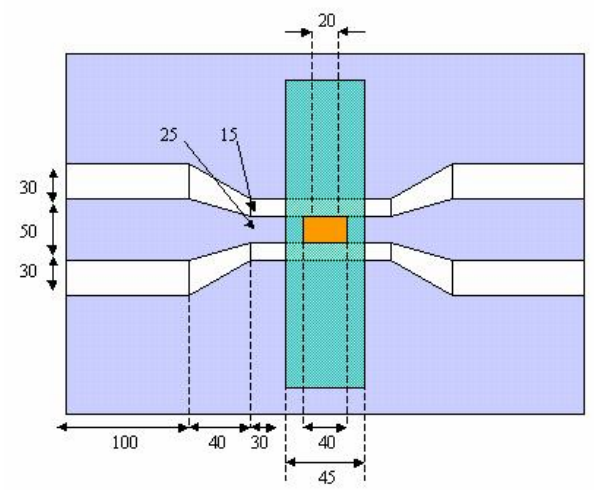

Fig. 3 Layout of a single switch. Dimensions are given in microns

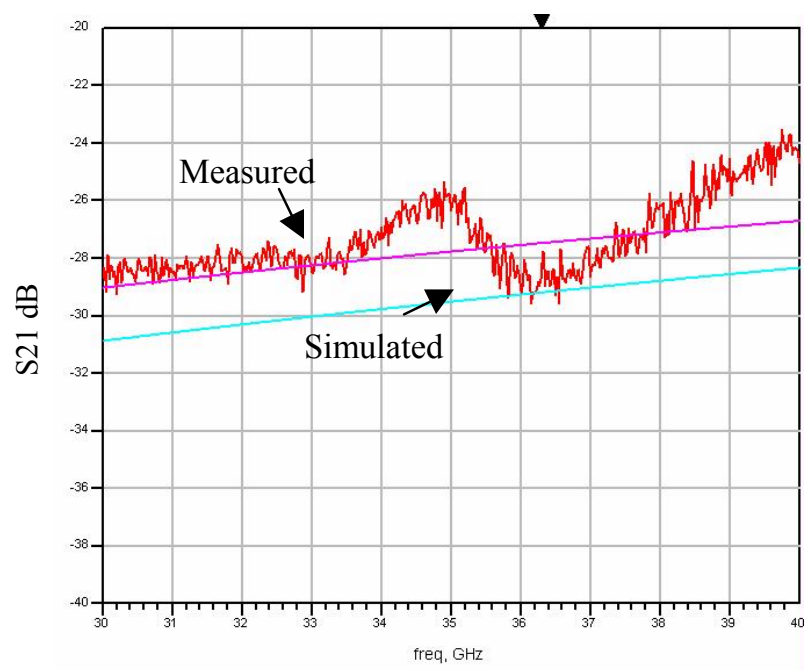

Fig. 4 Measured and simulated results in the off state for a single switch 


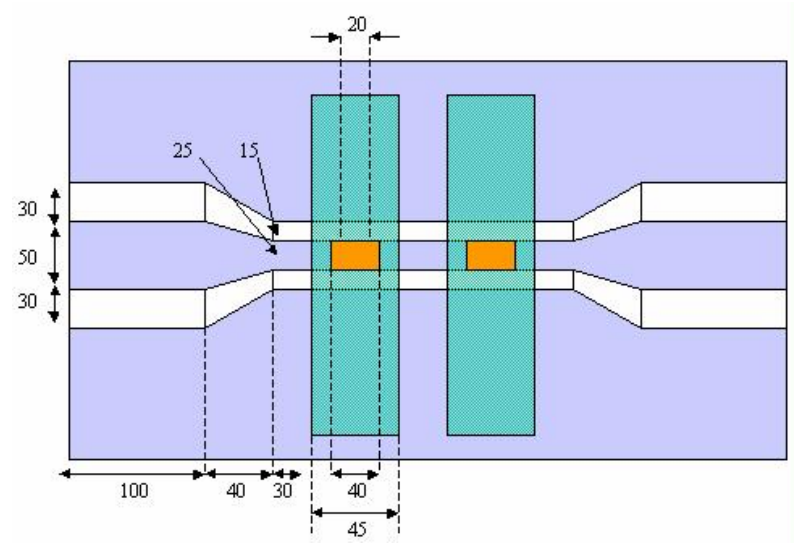

Fig. 5 Layout of a double series switch.

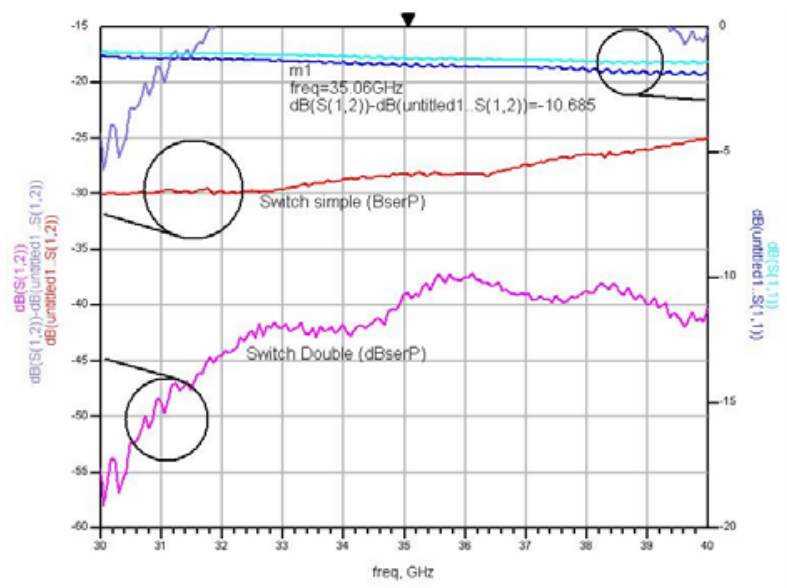

Fig. 6 Measured isolation of a single and a double series switch.

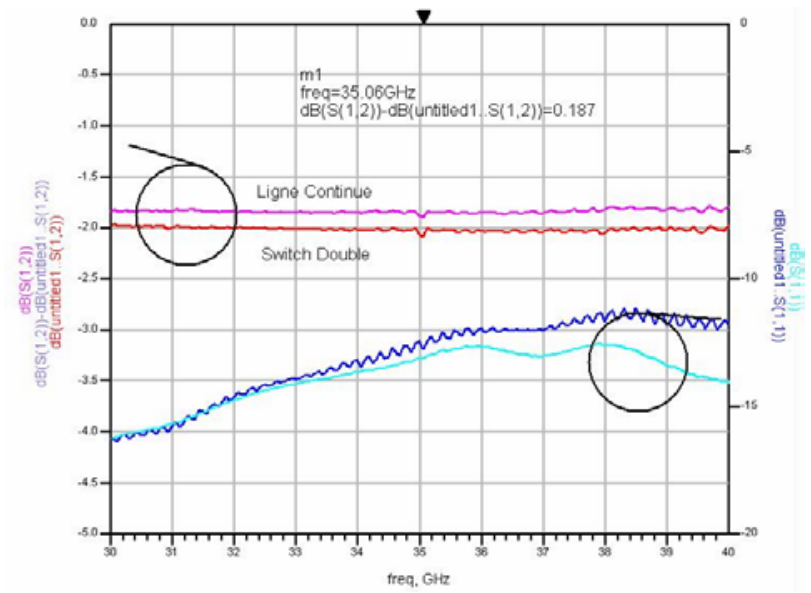

Fig. 7 On state loss of a double switch and a CPW line and return loss. 